\title{
Matching of varying-size form stimuli in the pigeon
}

\author{
RICHARD PISACRETA, CATHY POTTER, and PAUL LEFAVE \\ Ferris State College, Big Rapids, Michigan
}

Three pigeons were trained on the matching-to-sample task with 12 -mm form stimuli (a circle, a triangle, and a cross). After 105 acquisition sessions, the form stimuli were reduced in size to $8 \mathrm{~mm}$ for 65 sessions and then to $5 \mathrm{~mm}$ for 80 sessions. During the next phase, the samples were $12 \mathrm{~mm}$ in size and the comparison stimuli were 8-mm forms, or vice versa, 8-mm samples and 12-mm comparison stimuli. Finally, the samples and comparison stimuli were presented as growing (increasing from 5 to $12 \mathrm{~mm}$ ) or shrinking (decreasing from 12 to $5 \mathrm{~mm}$ ) forms. The birds learned to match the three different sizes of forms and matched well even when the sample and comparison stimuli were not the same size. They could not match samples only on the basis of direction of size change.

The simultaneous matching-to-sample (MTS) procedure has frequently been employed to assess conditional discrimination capabilities in nonhumans (e.g., Cumming \& Berryman, 1965; Ferster \& Appel, 1961; Zimmerman \& Ferster, 1963). At trial onset, a pigeon is presented with a sample stimulus projected onto the center key of a threekey response panel. A peck on the sample key produces a comparison stimulus (CO) on each of the two side keys. With all three keys now lighted, the bird's task is to peck the $\mathrm{CO}$ key presenting a stimulus that matches the sample. A peck on the matching $\mathrm{CO}$ key produces a reinforcer and the next trial. Mismatches are not reinforced. This study attempted to teach pigeons to (1) match form stimuli (a circle, a cross, and a triangle), (2) sustain matching levels regardless of the size of the samples and CO stimuli, and (3) match samples based on the direction of the size change.

Several reports have indicated that it is more difficult to establish matching sample forms than hue stimuli (e.g., Cumming \& Berryman, 1965; Farthing \& Opuda, 1974). In order to make the conditional discriminations as easy as possible, we employed the simultaneous MTS paradigm rather than the zero-delay MTS procedure. We also required that a fixed-ratio schedule be satisfied on the sample key before the CO stimuli were presented. Several papers have indicated that matching accuracy improves when ratio schedules are paired with the sample stimuli (Lydersen, Perkins, \& Chairez, 1977; Roberts \& Grant, 1976; Sacks, Kamil, \& Mack, 1972).

\section{METHOD}

\section{Subjects}

Three white Carneaux pigeons, maintained at $80 \% \pm 15 \mathrm{~g}$ of their free-

This study was supported by a faculty research grant to the first author. We would like to thank David Gough, Tim Lesneski, Lee Goodfellow, and Richard Cross for their assistance with data collection. Reprints may be obtained from Richard Pisacreta, Department of Psychology, Ferris State College, Big Rapids, MI 49307. feeding weights, were used. The pigeons had been previously trained to match figure stimuli but had not been previously exposed to the form stimuli employed in this study.

\section{Apparatus}

The apparatus was a $35 \times 35 \times 37 \mathrm{~cm}$ operant chamber enclosed in a sound-attenuating hull. The response panel, $37 \times 35 \mathrm{~cm}$, had nine 2.7-cm (BRS/LVE Model 121-16) response keys arranged in a $3 \times 3$ matrix. Only the lower three horizontal keys, located $2.5 \mathrm{~cm}$ above the feeder, were employed. Stimuli were rear-projected onto the keys by means of IEE inline projectors. (See Pisacreta and Rautio, 1984, for a more thorough description.) The feeder provided 4-sec access to grain. During sessions, illumination was provided only by the inline projectors. A ventilation fan and white noise delivered through the speaker masked extraneous noises. An E \& L Instruments MMD-1 computer and additional hardware recorded data and controlled experimental events.

\section{Procedure}

Phase 1 (105 sessions). At trial onset, the center key (the sample key) presented a randomly chosen circle, cross, or triangle. The circle was $12 \mathrm{~mm}$ in diameter. Each arm of the cross and each side of the triangle were $12 \mathrm{~mm}$ in length. Ten pecks (a fixed-ratio 10, FR 10, schedule) on the sample key lighted the two adjacent side keys with the $\mathrm{CO}$ stimuli. A peck to the matching comparison key produced a reinforcer, a 5-sec intertrial interval, and the next trial. An error (a peck to a nonmatching $\mathrm{CO}$ stimulus) recycled the trial by eliminating the $\mathrm{CO}$ stimuli, leaving only the sample present. The sample ratio had to again be satisfied before the $\mathrm{CO}$ stimuli were presented. This correction procedure repeated a trial indefinitely until a correct match had occurred. A session ended after 36 reinforced matches.

After 15 sessions, the sample ratio requirement was raised to FR 20 for 15 sessions; that is, 20 pecks were required on the sample key before the $\mathrm{CO}$ stimuli were presented. Finally, the sample ratio was increased to FR 30 for the remaining 75 sessions of Phase 1 .

Phase 2 (65 sessions). The FR 30 sample requirement was in effect for the remainder of the experiment. The sample and $\mathrm{CO}$ stimuli were reduced to $8 \mathrm{~mm}$ across in size.

Phase 3 (80 sessions). The forms measured $5 \mathrm{~mm}$ across when they were projected onto the response keys.

Phase 4 (65 sessions). The sample was a $12-\mathrm{mm}$ circle, cross, or triangle, and the $\mathrm{CO}$ stimuli were $8 \mathrm{~mm}$ in size during 28 of the 36 reinforced trials of each session. During the remaining 8 trials, the samples were $8 \mathrm{~mm}$ in size and the CO stimuli were $12 \mathrm{~mm}$ in size. For example, the sample was a $12-\mathrm{mm}$ circle. Thirty pecks on the sample produced two 8-mm CO stimuli-one circle and one cross (or triangle).

Phase 5 (33 sessions). The circle, cross, and triangle samples were 
not static as in previous phases. They appeared to increase (grow) or decrease (shrink) in size. For example, during some trials, the sample was a circle that increased in size from 5 to 8 to $12 \mathrm{~mm}$ across. The total transition time from small to large circle was $1 \mathrm{sec}$. After $300 \mathrm{msec}$, the growing circle (5- to 8- to 12-mm-across) stimuli were presented again and were repeated at 1 -sec intervals. Thirty pecks on this dynamic sample produced the dynamic $\mathrm{CO}$ stimuli, a growing circle and a growing cross (or triangle). The size of the three stimuli changed in unison. That is, the three keys simultaneously presented 5-, 8-, or $12-\mathrm{mm}$ stimuli. As before, a peck on the matching CO key produced a reinforcer, whereas a mismatch recycled the trial.

Phase 6 (25 sessions). During all the previous phases, the nomatching $\mathrm{CO}$ stimuli were always different forms; for example, if the sample was a growing or shrinking cross, the incorrect $\mathrm{CO}$ stimulus was a growing or shrinking triangle (or circle). During this last phase of the experiment, the nonmatching $\mathrm{CO}$ stimulus was the same form as the sample, but its direction of size change was the reverse of that exhibited by the sample and correct $\mathrm{CO}$ stimulus. For example, 30 pecks to a growing triangle (increasing from 5 to 8 to $12 \mathrm{~mm}$ ) produced a growing triangle on one $\mathrm{CO}$ key (the match) and a shrinking triangle (decreasing from 12 to 8 to $5 \mathrm{~mm}$ ) on the other CO key. A peck to the matching triangle, the one increasing in size synchronously with the sample, produced a reinforcer. A response to the shrinking triangle darkened the $\mathrm{CO}$ keys and repeated the trial.

\section{RESULTS}

Figure 1 shows the matching levels generated during Phases 1-3, inclusive. The first panel of Figure 1 shows that each bird maintained chance matching levels until the sample ratio was increased to FR 30 . These chance performances were produced by position preferences, which are not uncommon during initial MTS training (e.g., Carter \& Werner, 1978; Cumming \& Berryman, 1961). By the end of Phase 1, Birds B1, B2, and B3 were accurately matching the forms without error on $82 \%, 76 \%$, and $80 \%$ of the trials, respectively. During the last five sessions of Phase 1, Birds B1, B2, and B3 averaged 8, 11 , and 9 errors per session, respectively. During Phases

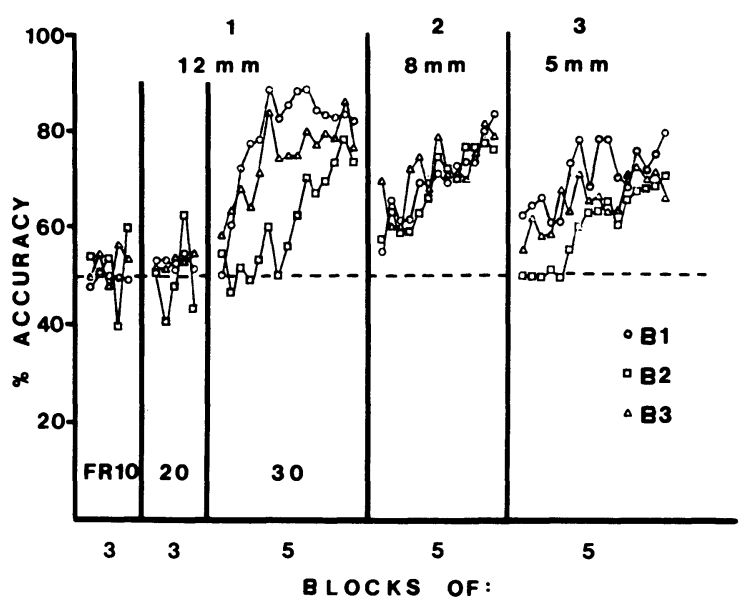

Figure 1. The percentage of trials during Phases 1-3 inclusive in which the first peck on a CO key was a correct match. Each data point represents the mean of three or five sessions, as indicated. FR = the fixed ratio required by the samples. The dotted line represents chance performance.

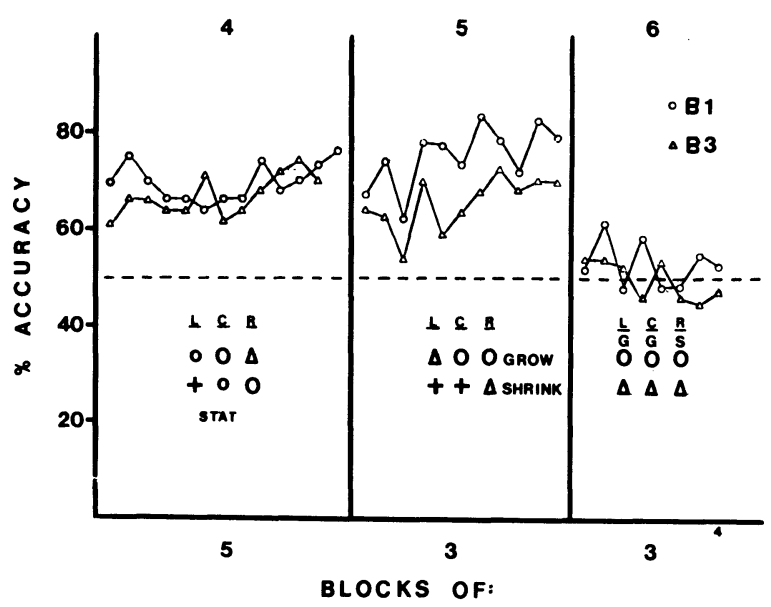

Figure 2. The percentage of trials during Phases 4-6 inclusive in which the first peck on a $\mathrm{CO}$ key was a correct match. The bottom of each panel displays examples of trials. $L, C$, and $R$ represent the $L$ (eft), C(enter), and R(ight) response keys. During Phase 4, the samples were 12-mm forms and the CO stimuli were 8-mm forms, or vice versa, 8-mm samples with 12-mm CO stimuli. Phase 5 presented forms that appeared to grow from 5 to $12 \mathrm{~mm}$, or shrink from 12 to $5 \mathrm{~mm}$, at 1-sec intervals. During Phase 6, the birds had to match on the basis of size change. For example, the last panel shows that the sample and left $\mathrm{CO}$ stimulus could be G(rowing) circles, whereas the incorrect $\mathrm{CO}$ stimulus during that trial was a S(hrinking) circle.

2 and 3, each bird showed initial matching accuracy decrements followed by a gradual recovery in matching performance. Although Phases 2 and 3 employed only smaller representations of the same form stimuli used in Phase 1, each bird produced acquisition curves similar to those produced when birds are presented with novel hues or stimuli orthogonal to the training stimuli. Bird B2 developed a respiratory infection and was retired at the end of Phase 3.

Figure 2 shows the matching levels generated during Phases 4-6, inclusive. Panel 1, Phase 4, of Figure 2 shows that although the sample and CO stimuli were of unequal size, the pigeons produced matching levels during Phase 4 that were comparable to those levels maintained at the end of Phase 3. Matching accuracies for Birds B1 and B3 were approximately $76 \%$ and $70 \%$, respectively. Due to a respiratory infection, Bird B3 did not complete the last five sessions of this phase. Similar results were yielded during Phase 5, in which the samples and $\mathrm{CO}$ stimuli were growing or shrinking forms. By the end of the phase, Birds B1 and B3 were matching the dynamic samples with accuracies of approximately $78 \%$ and $70 \%$, respectively.

During Phase 6, in which direction of size change was the only salient matching cue, each bird performed at chance level during $50 \%$ of the sessions. The results suggest that birds can learn to discriminate between different forms and changes in form size. They cannot, however, come under the control of direction of size change alone, that is, growing or shrinking identical stimuli. 


\section{DISCUSSION}

The present study shows that pigeons will (1) learn to match differentsized form stimuli, (2) learn to match samples by form type (e.g., circle) even though the $\mathrm{CO}$ stimulus is larger or smaller than the sample, although they (3) show little evidence of matching transfer from one form size to another, and (4) cannot match on the basis of direction of size change alone.

Although the only difference between Phases 1, 2, and 3 was a reduction in stimulus size, each bird required $45-80$ sessions to reestablish previous matching levels. These transfer performances were poorer than those reported by Cerella (1979), Herrnstein, Loveland, and Cable (1976), Pisacreta, Redwood, and Witt (in press), and Poole and Lander (1971), all of whom employed complex, rather than simple, stimuli, that is, pictures of oak leaves, trees, bodies of water, people, birds, and various other items. These decreases in matching performance during the initial sessions of Phases 2 and 3 occurred even though each bird had successfully completed 17,000 matching trials in a previous study and over 4,000 trials with the $12-\mathrm{mm}$ forms during Phase 1 of the present experiment. Several other papers have also reported little or no transfer of matching (Carter \& Werner, 1978; Cumming \& Berryman, 1961; Farthing \& Opuda, 1974). The present work appears to support the multiple-rule model, or matching as a case of concomitant chains position (Carter \& Eckerman, 1976; Carter \& Werner, 1978; Farthing \& Opuda, 1974; Premack, 1978). The multiplerule model postulates that our birds learned three two-component chains: If the sample was a $12-\mathrm{mm}$ circle, cross, or triangle, then peck the 12$\mathrm{mm}$ circle, cross, or triangle $\mathrm{CO}$ stimulus, respectively. When the forms were reduced in size during Phases 2 and 3, the initial decreases in matching accuracies suggest that the birds had to learn a new set of chains for each change in form size. The performances in Phases 4 and 5 could be explained by generalization mechanisms and a reinforcement history with the stimuli involved. On the basis of these results, one is tempted to conclude that conceptual capability in the pigeon is extremely limited, if present at all (see Premack, 1978).

We do not believe this is the case. An alternate view is that the MTS procedure reinforces chained behavior, rather than the acquisition of conceptual matching. Facilitated MTS transfer requires that the subject be capable of making same-different discriminations (Premack, 1978). Employing modified MTS procedures, several researchers have demonstrated that pigeons can make same-different decisions and show matching transfer (Honig, 1965; Malott \& Malott, 1970; Pisacreta et al., 1984; Pisacreta \& Witt, 1983; Urcuioli \& Nevin, 1975). If three-key discriminations or two-component chains reliably produce reinforcement, why should the pigeon learn a generalized matching concept? Schwartz (1982) showed that even human subjects would not learn a rule if repetitions of a simple chain reliably produced rewards. It is possible that conceptualtype learning may require contingencies more complex than those present in the standard MTS situation. Simple tasks may fail to produce anything beyond simple associative learning. This apparently was the case in the present study. The matching performance of our birds was disrupted by a $4-\mathrm{mm}$ change in stimulus size. Conceptual-type learning may require situations so complex that a rule must be learned in order to reliably produce reinforcers (e.g., Fujita, 1983; Herrnstein et al., 1976; Holmes, 1979; Pisacreta et al., 1984).

\section{REFERENCES}

Carter, D. E., \& Eckerman, D. A. (1976). Reply to Zentall and Hogan. Science, 191, 409.

CARTER, D. E., \& WeRner, T. J. (1978). Complex learning and information processing by pigeons: A critical analysis. Journal of the Experimental Analysis of Behavior, 29, 565-601.

Cerella, J. (1979). Visual classes and natural categories in the pigeon.
Journal of Experimental Psychology: Human Perception and Performance, 5, 68-77.

Cumming, W. W., \& Bekryman, R. (1961). Some data on matching behavior in the pigeon. Journal of the Experimental Analysis of $\mathrm{Be}$ havior, 4, 281-284.

Cumming, W. W., \& Berryman, R. (1965). The complex discriminated operant: Studies of matching-to-sample and related problems. In D. I. Mostofsky (Ed.), Stimulus generalization (pp. 284-330). Stanford, CA: Stanford University Press.

FARTHING, G. W., \& OPUDA, M. J. (1974). Transfer of matching-tosample in pigeons. Journal of the Experimental Analysis of Behavior, 21, 199-213.

FERSTER, C. B., \& APPEL, J. B. (1961). Punishment of $S^{\Delta}$ responding in matching to sample by timeout from positive re inforcement. Journal of the Experimental Analysis of Behavior, 4, 45-56.

Fujita, K. (1983). Acquisition and transfer of a higher-order conditional discrimination performance in the Japanese monkey. Japanese Psychological Research, 25, 1-8.

Herrnstein, R. J., Loveland, D. H., \& Cable, C. (1976). Natural concepts in the pigeon. Journal of Experimental Psychology: Animal Behavior Processes, 2, 285-311.

Holmes, P. W. (1979). Transfer of matching performance in pigeons. Journal of the Experimental Analysis of Behavior, 31, 103-114.

HoNIG, W. K. (1965). Discrimination, generalization, and transfer on the basis of stimulus differences. In D. I. Mostofsky (Ed.), Stimulus generalization (pp. 218-254). Stanford, CA: Stanford University Press.

Lydersen, T., Perkins, D., \& Chairez, H. (1977). Effects of fixed ratio sample and choice response requirements upon oddity matching. Journal of the Experimental Analysis of Behavior, 27, 97-101.

MalotT, R. W., \& MalotT, M. K. (1970). Perception and stimulus generalization. In W. C. Stebbins (Ed.), Animal psychophysics: The design and conduct of sensory experiments (pp. 368-400). New York: Appleton-Century-Crofts.

PisaCRETA, R., \& RAUTIO, J. (1984). Effects of sample-specific ratios on free-choice matching-order sequences. Bulletin of the Psychonomic Society, 22, 244-247.

Pisacreta, R., RedWOOd, T., \& WITT, K. (1984). Transfer of matching to figure samples in the pigeon. Journal of the Experimental Analysis of Behavior, 42, 223-237.

Pisacreta, R., \& WITT, K. (1983). Same-different discriminations in the pigeon. Bulletin of the Psychonomic Society, 21, 411-414.

Poole, J., \& LANDER, D. G. (1971). The pigeon's concept of people. Psychonomic Science, 25, 157-158.

Premack, D. (1978). On the abstractness of human concepts: Why it would be difficult to talk to a pigeon. In S. H. Hulse, H. Fowler, \& W. K. Honig (Eds.), Cognitive processes in animal behavior (pp. 423-451). Hillsdale, NJ: Erlbaum.

RoBERTS, W. A., \& GRANT, D. S. (1976). Studies of short-term memory in the pigeon using the delayed matching-to-sample procedure. In D. I. Medin, W. A. Roberts, \& R. T. David (Eds.), Processes of animal memory (pp. 79-112). Hillsdale, NJ: Erlbaum.

SACKS, R. A., KAMIL, A. C., \& MACK, R. (1972). The effects of fixed ratio sample requirements on matching-to-sample in the pigeon. Psychonomic Science, 26, 291-293.

SCHWARTZ, B. (1982). Reinforcement-induced behavioral stereotypy: How not to teach people to discover rules. Journal of Experimental Psychology: General, 111, 23-59.

UrCuioli, P. J., \& NeVIN, J. A. (1975). Transfer of hue matching in pigeons. Journal of the Experimental Analysis of Behavior, 24, 149-155.

Zimmerman, J., \& Ferster, C. B. (1963). Intermittent punishment of $\mathrm{S}^{\Delta}$ responding in matching to sample. Journal of the Experimental Analysis of Behavior, 6, 349-356.

(Manuscript received for publication August 30, 1984.) 